\title{
Cultivating the Research Environment to Enhance Quality of Life of Academics in an University Setting
}

\author{
Dian Ratna Sawitri*, Harlina Nurtjahjanti, and Anggun Resdasari Prasetyo \\ Faculty of Psychology, Diponegoro University, Semarang, 50275, Indonesia
}

\begin{abstract}
Background: In the university, one of the most important organizational climate which affects academics' behavior is research environment. This study aimed to examine the relationships between perceived research environment, research self-efficacy, and quality of life of academics. Method: We surveyed 100 academics from a state university in Semarang, using measures of research environment, research self-efficacy, research burn-out, and life satisfaction. We examined whether the relationships between perceived research environment and research burn-out and life satisfaction was mediated by research self-efficacy. Results: Structural equation modelling demonstrated that a good support for a model that revealed significant ways by which individual and contextual variables were associated with quality of life. The measurement model, $\chi^{2}(108)=204.57, p<.001, \chi^{2} / \mathrm{df}=1.79$, $\mathrm{CFI}=.94, \mathrm{RMSEA}=.06$ demonstrated good fit statistics, with factor loading ranging from .40 to $.85(p<.001)$ The hypothesized structural model also showed good fit statistics, $\chi^{2}(153)=270.87, p<.001, \chi^{2} / \mathrm{df}=1.57$, $\mathrm{CFI}=.95, \mathrm{RMSEA}=.05$. Perceived research environment was positively associated with research self-efficacy $(\beta=.34, p<.001)$, research self-efficacy was associated negatively with research burn-out $(\beta=-.33, p<.001)$, and research self-efficacy was associated positively with life satisfaction $(\beta=.40, p<.001)$. Conclusion: The findings demonstrated that perceived research environment is an important variable that can have positive effects in developing research self-efficacy, enhancing life satisfaction, and reducing research burn-out.
\end{abstract}

Keywords: Perceived Research Environment, Quality of Life, Research Self-Efficacy, Stress, Academics.

\section{INTRODUCTION}

In the context of research engagement in academics, universities need to improve organizational climates in order to create a satisfying profession. ${ }^{1}$ Organizational climate may either facilitate academics' participation and effectiveness in teaching, research and scholarly activities or create barriers to this participation. ${ }^{2}$ One aspect of organizational climate in the university setting can be understood through how the academics perceive their environment as research supportive. A focus in research environment firstly raised in 1980's in the scientist-practitioner model work setting, such as in nursing and psychology.

Several characteristics of productive research environment in nursing have been revealed in previous study, ${ }^{3}$ and attitude toward nursing research and research training in clinical setting also has been investigated. ${ }^{4}$

Further, in the 1990's, interest in research competence of people working in the university setting emerged, and it involved counselling psychology doctoral students, and simultaneously, in the career area, social cognitive career theory (SCCT) was developed. This theory explains the developmental processes of

*Author to whom correspondence should be addressed. interests, choice, and performance outcomes in the career and education domains. The theory highlights several specific person mechanisms that operate as co-determinants of behaviour, which are particularly relevant to career development. It also identifies contextual influences in the implementation of career action behaviours. ${ }^{5}$ Previous researchers used SCCT as a theoretical framework for the first time to explain interest in research in doctoral psychology students. ${ }^{6,7}$ While the relationship between research environment and self-efficacy in previous studies was robust, these variables have not been tested in academics, especially in relation with research burn out and life satisfaction.

\section{METHOD}

Participants were 100 academics from a state university in Semarang. The data were collected using research environment, research self-efficacy, research burn-out, and life satisfaction scales. Research environment scale was used to assess perceived research environment. Items for this scale were generated following a review of the literature and after a series of six focus groups. The first author and one research assistant conducted the focus groups with 40 academics from a state university in Central Java, Indonesia. They came from the departments of medical, 
sciences, engineering, economics, linguistics, and psychology. The aims of the focus groups were to engage with the target participants to enhance the content validity of the scale items and to help validate the key dimensions of the construct. The academics were asked to discuss their own concept of research environment, their research expectations, factors that encourage and impede them to conduct research, support from the university for them to conduct research. The focus groups were audio-taped for later reference.

The 38-item Research Self-Efficacy Scale was used to measure research confidence. ${ }^{8}$ Participants were asked to rate the degree to which they feel confident in their ability to accomplish each item, such as "Discuss research ideas with peers" on a scale ranging from 0 (not confident) to 100 (totally confident). A 6-item research-related burn-out scale was used to assess burn-out attributed to research matters. ${ }^{9}$ Participants responded to items such as, "I don't think I have in me what it takes to be a successful academic researcher," on a 5-point scale $(1=$ strongly disagree and $5=$ strongly agree). Life satisfaction was measured using the Satisfaction with Life Scale. ${ }^{10}$ Participants were asked to rate satisfaction with their lives on 5 statements such as, "In most ways my life is close to my ideal," on a 5-point scale $(1=$ strongly disagree and $5=$ strongly agree $)$.

\section{RESULTS}

We used latent variable analysis (maximum likelihood estimation using AMOS V21) to test the hypothesized structural model. We represented the latent variables using a mixed of observed items and multi-item parcels to meet ideal ratios of sample size to parameters estimated $(20: 1){ }^{11}$ The measurement model, $\chi^{2}(108)=204.57, p<.001, \chi^{2} / \mathrm{df}=1.79, \mathrm{CFI}=.94, \mathrm{RMSEA}=$ .06 demonstrated good fit statistics, with factor loadings ranging from .40 to $.85(p<.001)$.

We also found good fit statistics for the hypothesized structural model, $\chi^{2}(153)=270.87, p<.001, \chi^{2} / \mathrm{df}=1.57, \mathrm{CFI}=$ .95 , RMSEA $=.05$. All paths were significant: perceived research environment $\rightarrow$ research self-efficacy $(\beta=.34, p<.001)$, research self-efficacy $\rightarrow$ research burn-out $(\beta=-.33, p<.001)$, research self-efficacy $\rightarrow$ life satisfaction $(\beta=.40, p<.001)$.

\section{DISCUSSION}

This study investigated the relationships between perceived research environment, research self-efficacy, research burn-out, and life satisfaction. We assessed a sample of academics and used the SCCT framework. ${ }^{5}$

We found that perceived research environment was associated positively with research self-efficacy $(\beta=.34, p<.001)$. This suggests that those who perceive that their environment was conducive for conducting research activities were more likely to develop higher confidence in carrying-out research-related tasks. This finding is consistent with previous studies. ${ }^{12,13}$

Finally, we found that research self-efficacy was negatively associated with research burn-out and positively associated with life satisfaction. This finding suggests that those who are more confidence in conducting research are more likely to have less experience of negative emotional state. This negative emotional state is associated with long-term stresses in the academic research and publication processes that will cause them cannot do or will not do research activities anymore. Those who are more efficacious in carrying-out research-related activities are also more likely to have higher satisfaction with their lives $(\beta=$ $.40, p<.001)$. These findings are consistent with previous studies, which demonstrated that one of several major causes of burnout is lack of control over establishing and conducting day-to-day activities, which is in this case, research-related activities. ${ }^{14}$

These findings suggest that academics need to be aware that how they perceive their research environment is crucial in developing their research confidence, and in turn, this will reduce burn-out related to research and increase their life satisfaction. Therefore, they also should be able to assemble their environment to be supportive for them. Most importantly, the institution need to develop a conducive research environment to develop the academics self-efficacy. Conducive research environment can have positive effects on research self-efficacy, which is finally able to reduce research burn-out and to increase life satisfaction.

This study examined the well-supported SCCT model containing perceived research environment, research self-efficacy, research burn-out, and life satisfaction in a sample of academics. Participants of this study were drawn from one university using a convenience sampling technique, that might reduce the external validity of the findings. Hence, there is a need to be careful when generalising the results to other groups of academics from other universities. Finally, this study is cross-sectional and this does not allow us to confirm the causal relationship among the study variables.

\section{CONCLUSION}

Based on the findings, it can be concluded that those who perceive that their research environment is supportive are more likely to have higher confidence in conducting research activities. This research-related confidence then leads them to experience less research-related burn-out and to have higher levels of life satisfaction. The findings highlighted the important contribution for perceived research environment and research self-efficacy in academics' quality of life in a university setting. The results also highlighted the important role of the university in cultivating the research environment.

\section{References and Notes}

1. S. Peterson and F. Wiesenberg, International Journal of Lifelong Education 23 (2004).

2. A. McMurray and D. Scott, Higher Education Research and Development 32 (2013).

3. M. F. Pranulis and S. R. Gortner, Western Journal of Nursing Research 7 (1985).

4. G. W. Marsh and T. L. Brown, Journal of Clinical Noursing 1 (1992).

5. R. W. Lent, S. D. Brown, and G. Hackett, Journal of Vocational Behavior 45 (1994).

6. B. Mallinckrodt, C. J. Gelso, and G. M. Royalty, Professional Psychology: Research and Practice 21 (1990)

7. R. M. Bishop and K. J. Bieschke, Journal of Counseling Psychology 45 (1998).

8. A. T. Greeley, E. Johnson, and S. Seem, M. Braver, L. Dias, K. Evans, and P. Pricken, Research self-efficacy scale, Unpublished Scale, The Pennsylvania State University, University Park (1989).

9. S. N. Singh, S. Mishra, and D. Kim, Psychological Reports 83 (1998).

10. E. Diener, R. A. Emmons, R. J. Larsen, and S. Griffin, Journal of Personality Assessment 49 (1985)

11. R. B. Kline, Principles and Practice of Structural Equation Modeling (3rd ed.), The Guildford Press, New York (2011)

12. J. H. Kahn and N. A. Scott, The Counseling Psychologist 25 (1997).

13. J. C. Phillips, R. H. Russell, The Counseling Psychologist 22 (1994)

14. C. Maslach and M. P. Leiter, Psychology Today 32 (1999).

Received: 12 October 2016. Revised/Accepted: 24 December 2016. 